Open Access

\title{
Optimization of combined temozolomide and peptide receptor radionuclide therapy (PRRT) in mice after multimodality molecular imaging studies
}

Sander M. Bison ${ }^{1,2^{*+}}$, Joost C. Haeck ${ }^{1,2+}$, K. Bol ${ }^{2,3}$, S. J. Koelewijn ${ }^{1}$, H. C. Groen ${ }^{1}$, M. Melis ${ }^{1}$, J. F. Veenland ${ }^{2,3}$, M. R. Bernsen ${ }^{1,2}$ and M. de Jong ${ }^{1,2}$

\begin{abstract}
Background: Successful treatments of patients with somatostatin receptor (SSTR)-overexpressing neuroendocrine tumours (NET) comprise somatostatin-analogue lutetium-177-labelled octreotate ( ${ }^{177}$ Lu-TATE) treatment, also referred to as peptide receptor radionuclide therapy (PRRT), and temozolomide (TMZ) treatment. Their combination might result in additive effects. Using MRI and SPECT/CT, we studied tumour characteristics and therapeutic responses after different (combined) administration schemes in a murine tumour model in order to identify the optimal treatment schedule for PRRT plus TMZ.

Methods: We performed molecular imaging studies in mice bearing SSTR-expressing H69 (humane small cell lung cancer) tumours after single intravenous (i.v.) administration of $30 \mathrm{MBq}{ }^{177}$ Lu-TATE or TMZ (oral $50 \mathrm{mg} / \mathrm{kg}$ daily for 14 days). Tumour perfusion was evaluated weekly by dynamic contrast-enhanced MRI (DCE-MRI), whereas tumour uptake of ${ }^{111}$ In-octreotide was quantified using SPECT/CT until day 39 after treatment. Based on these results, seven different ${ }^{177}$ Lu-octreotate and TMZ combination schemes were evaluated for therapy response, varying the order and time interval of the two therapies and compared with single treatments.

Results: PRRT and TMZ both resulted in tumour size reduction, accompanied by significant changes in MRI characteristics such as an enhanced tumour perfusion. Moreover, TMZ treatment also resulted in increased uptake of the SST analogue ${ }^{111}$ In-octreotide until day 13 . In the subsequent therapy study, $90 \%$ of animals receiving ${ }^{177} \mathrm{Lu}$ TATE at day 14 after TMZ treatment showed complete response, being the best anti-tumour results among groups. Conclusions: Molecular imaging studies indicated that PRRT after TMZ treatment could induce optimal therapeutic effects because of enhanced tumour uptake of radioactivity after TMZ, which was confirmed by therapy responses. Therefore, clinical translation of TMZ treatment prior to PRRT might increase tumour responses in NET patients as well.
\end{abstract}

Keywords: NETs, PRRT, Temozolomide, Combination therapy, Multimodality imaging, Tumour perfusion

\footnotetext{
* Correspondence: s.bison@eramusmc.nl

Sander M. Bison and Joost C. Haeck are the first authors.

${ }^{\dagger}$ Equal contributors

'Department of Nuclear Medicine, Erasmus MC, Postbus 2040, Rotterdam

3000, CA, The Netherlands

2Department of Radiology, Erasmus MC, Postbus 2040, Rotterdam 3000, CA,

The Netherlands

Full list of author information is available at the end of the article
} 


\section{Background}

Systemic internal radiation therapy using radiolabelled peptides, specifically targeting receptors overexpressed on tumour cells, is an attractive cancer treatment. A high absorbed radiation dose is being delivered to tumours with a tolerable toxicity in normal non-targeted tissues. This so-called peptide receptor radionuclide therapy (PRRT) has been shown to be a most effective treatment option for patients with SSTR-expressing neuroendocrine tumours (NETs) [1-3].

Most NETs are slowly proliferating tumours, making them relatively resistant to most chemotherapeutics. In more than $50 \%$ of the patients, NETs are diagnosed at a relatively late stage, often with metastatic spread [4], which leaves little chance for curative surgery. Then, PRRT with radiolabelled SST analogues appeared to be an attractive cancer treatment. A high absorbed dose is being delivered to tumours with a tolerable toxicity in normal non-targeted tissues [1-3]. Radiolabelled SST analogues, such as ${ }^{111}$ In-DTPA-octreotide $\left({ }^{111}\right.$ In-octreotide) or ${ }^{177} \mathrm{Lu}-\mathrm{DOTA}, \mathrm{Tyr}^{3}$-octreotate $\left({ }^{177} \mathrm{Lu}\right.$-TATE), show a high binding affinity for the somatostatin receptor type 2 (SSTR2), which is overexpressed on the vast majority of NETs [5].

PRRT has proven to be an effective therapy in most patients with NETs $[1,6]$. Nevertheless, despite the improvement of progression-free survival and quality of life, complete remissions after PRRT are still rare. A combination of PRRT with radio-sensitizing chemotherapeutics, such as capecitabine (5-fluorouracil) or temozolomide (TMZ), might induce synergistic effects [7-9]. Currently, phase II clinical trials combining PRRT, using ${ }^{177} \mathrm{Lu}-\mathrm{TATE}$ and capecitabine or both capecitabine and TMZ, are ongoing. The first analyses showed promising results $[8,10]$.

When PRRT with chemotherapeutics are being combined, also potential negative interactions between the two therapies should be taken into consideration. Chemotherapy might affect the SSTR2 expression on tumour cells, on which PRRT depends for targeting of radionuclides, for example [11, 12]. Moreover, tumour vasculature might be affected by chemotherapy whereas efficient/adequate tumour perfusion is required for local delivery of ${ }^{177}$ Lu-TATE [13]. To obtain an optimal therapeutic scheme for the combination of PRRT and TMZ, information on the aforementioned tumour characteristics during treatment is required, which was the aim of this pre-clinical study using an H69-tumour-bearing mouse model. Tumour perfusion was monitored by dynamic contrast-enhanced (DCE)-MRI and SSTR expression by ${ }^{111}$ In-octreotide SPECT. The results from these imaging studies were applied in the design of different therapeutic schemes to stratify maximum therapeutic efficacy using TMZ and PRRT.

\section{Methods}

\section{Experimental setup}

We have started a pilot study in which H69 tumourbearing mice were treated with increasing amounts of ${ }^{177} \mathrm{Lu}$-TATE to determine which dose resulted in clear tumour responses but without complete cure to allow detection of additional effects during combination therapy. Three groups $(n=7)$ of H69-tumour-bearing mice were treated with 10,20 or $30 \mathrm{MBq}{ }^{177} \mathrm{Lu}$-TATE and compared with untreated control animals. Monitoring of body weight and tumour size was performed until day 28 after the start of treatment.

For TMZ treatment, different dosing schedules have been reported, including a total administered dose of $>1000 \mathrm{mg} / \mathrm{kg}$ [14] or the administration of one or more cycles during 5 days, in which a dose of 50 or $120 \mathrm{mg} / \mathrm{kg} /$ day was administered $[15,16]$. Since we planned to administer only one cycle, we used a dose of $50 \mathrm{mg} / \mathrm{kg} /$ day for 2 weeks, to study the effects of TMZ treatment in the H69 model, supplemented with investigations into combination of PRRT and TMZ. In this study, the earlier determined optimal dose of $30 \mathrm{MBq}{ }^{177} \mathrm{Lu}$-TATE was used.

\section{Imaging studies to determine tumour characteristics during PRRT or TMZ treatment}

Three groups of mice were included in this imaging study (Table 1). The PRRT group received a single dose of $50 \mathrm{MBq}{ }^{177} \mathrm{Lu}$-TATE on day 1 , and the TMZ group was treated with $50 \mathrm{mg} / \mathrm{kg} \mathrm{TMZ}$ administered orally for 2 weeks, starting at day 0 . The control group received saline. The timeline for these studies is shown in Fig. 1a.

PRRT group Mice $(n=4)$ received a baseline DCE-MRI scan 1 day prior to administration of $50 \mathrm{MBq}{ }^{177} \mathrm{Lu}$ TATE. During follow-up of the therapy, MRI scans were acquired on days 4, 7, 11, 15, 20 and 28. Moreover, a SPECT/CT scan to determine the tumour uptake of ${ }^{177} \mathrm{Lu}$-TATE was performed $24 \mathrm{~h}$ after administration.

TMZ group Mice $(n=7)$ received one baseline DCEMRI scan 2 days prior start of TMZ treatment, which was repeated once weekly during and after TMZ treatment until day 28. To determine the level of radiopeptides uptake, ${ }^{111}$ In-octreotide SPECT/CT scanning was performed 1 day prior start of TMZ treatment and repeated once weekly for 6 weeks during and after TMZ. At day 1 (before TMZ), day 14 (after TMZ) and day 28, when tumours showed maximal response, three mice where sacrificed to collect the H69 xenograft to determine the level of SSTR expression by in vitro autoradiography using ${ }^{111}$ In-octreotide. 
Table 1 Treatment and imaging for each group

\begin{tabular}{llll}
\hline Group & Number of mice & Treatment & Imaging \\
\hline${ }^{177}$ Lu-TATE & 4 & $50 \mathrm{MBq}{ }^{177}$ Lu-TATE i.v. & $6 \times$ MRI, $1 \times$ SPECT/CT \\
TMZ & 7 & TMZ $50 \mathrm{mg} / \mathrm{kg} \mathrm{p.o.} \mathrm{for} 14$ days & $7 \times \mathrm{MRI}, 7 \times$ SPECT/CT \\
Control & 3 & Saline & $3 \times$ MRI \\
\hline
\end{tabular}

${ }^{177}$ Lu-TATE lutetium-177-labelled octreotate, TMZ temozolomide

Control group Non-treated mice $(n=3)$ received four DCE-MRI scans: at days 1,5 and 12 .

\section{Combination therapy of PRRT and TMZ}

Seven groups of mice were included to compare H69 responses after different combination treatment schedules, including a placebo control group (receiving oraplus solution without TMZ p.o. once daily.) (Table 2). Uptake of ${ }^{177} \mathrm{Lu}$-TATE was quantified in three to six tumours of each group after PRRT by SPECT imaging. The timeline for these studies is shown in Fig. 1b.

Tumour cell line

The SSTR2-expressing human small cell lung cancer cell line H69 was obtained from ECACC (Salisbury, UK) and grown in RPMI medium (Gibco, Invitrogen Corp.,

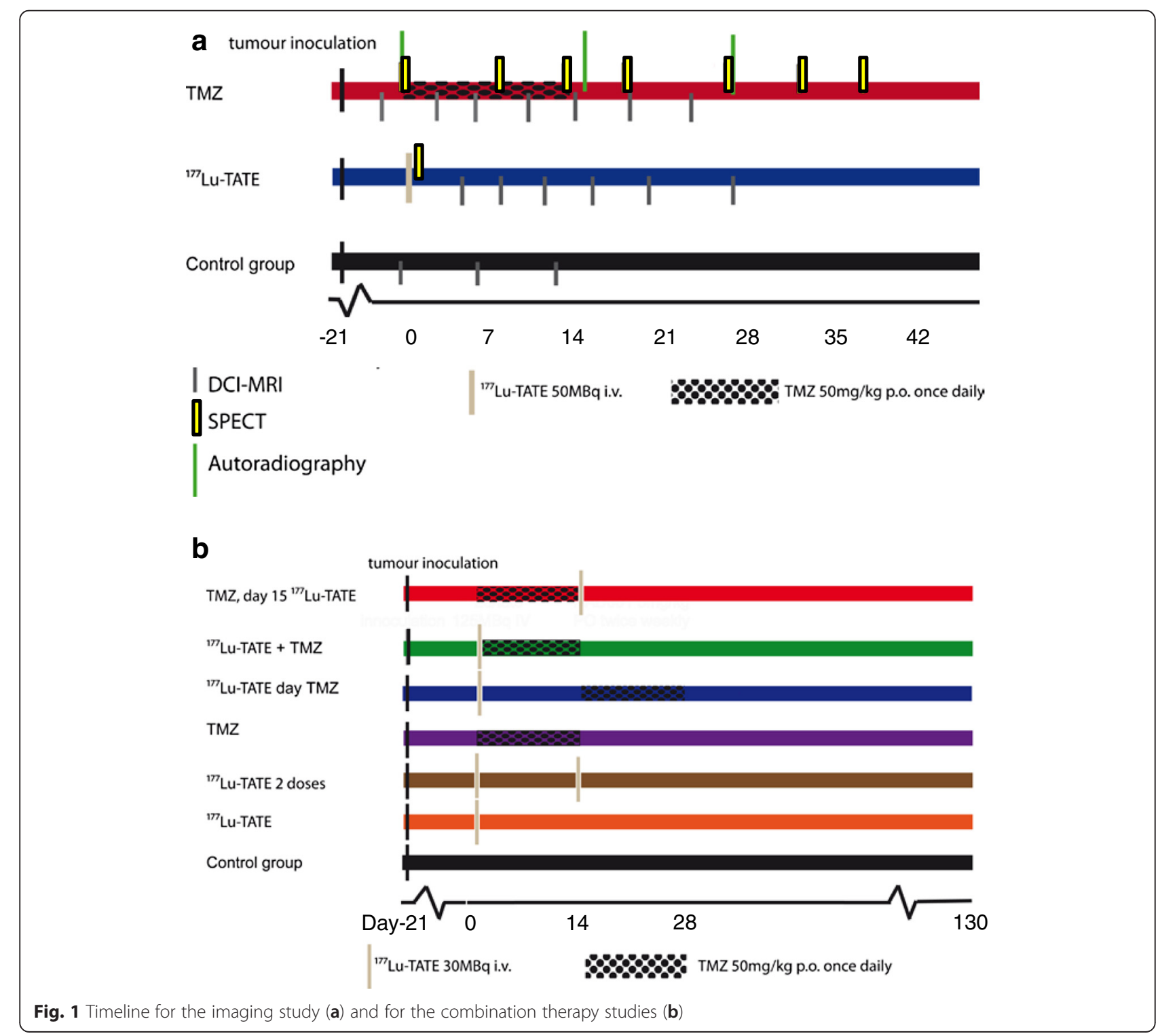


Table 2 Treatment schedule and number of mice for each group

\begin{tabular}{|c|c|c|c|}
\hline \multirow[t]{2}{*}{ Group } & \multicolumn{2}{|l|}{ Treatment } & \multirow[t]{2}{*}{ Number of mice } \\
\hline & ${ }^{177}$ Lu-TATE & TMZ & \\
\hline Control & - & Placebo & 5 \\
\hline 1: PRRT single & $30 \mathrm{MBq}$ day 0 & Placebo & 8 \\
\hline 2: PRRT double & $30 \mathrm{MBq}$ day 0 & Placebo & 8 \\
\hline 3: TMZ & - & $50 \mathrm{mg} / \mathrm{kg}$ for 14 days from day 0 & 8 \\
\hline 4: PRRT + TMZ at day 14 & $30 \mathrm{MBq}$ day 0 & $50 \mathrm{mg} / \mathrm{kg}$ for 14 days from day 14 & 8 \\
\hline 5: PRRT + TMZ & $30 \mathrm{MBq}$ day 0 & $50 \mathrm{mg} / \mathrm{kg}$ for 14 days from day 0 & 8 \\
\hline 6: TMZ + PRRT at day 14 & $30 \mathrm{MBq}$ day 14 & $50 \mathrm{mg} / \mathrm{kg}$ for 14 days from day 0 & 10 \\
\hline
\end{tabular}

${ }^{177}$ Lu-TATE lutetium-177-labelled octreotate, TMZ temozolomide, PRRT peptide receptor radionuclide therapy

Breda, The Netherlands) supplemented with $10 \%$ heatinactivated foetal bovine serum.

\section{Animals and tumour model}

All animal experiments have been conducted with prior approval of the animal ethics committee of our institution and performed in accordance with Dutch laws. Male NMRI nu/nu mice (body weight $\sim 33 \mathrm{~g}$ ) were obtained from Harlan (Heerlen, the Netherlands). One week after arrival, at the age of 5-7 weeks, mice were inoculated subcutaneously with $10^{7} \mathrm{H} 69$ cells in $0.2-\mathrm{ml}$ HBSS. For all experiments, animals were randomized into matching treatment groups regarding tumour size at the start of treatment 4 weeks after tumour inoculation. Randomized treatment groups were created by matched pairs randomization. Three times a week, mice were weighed and length and width of the tumour were measured using a calliper by a person blinded for the treatment. Tumour volume was calculated using the formula 0.5 (length $\times$ width) ${ }^{1.5}$ adapted from the SWOG criteria. Mice were euthanized when $>10 \%$ loss of body weight (BW) since start of the experiment was observed or when tumour volume exceeded $1800 \mathrm{~mm}^{3}$.

\section{Chemotherapeutics}

Temozolomide was obtained from Sun Pharmaceutical Industries Europe B.V. (Hoofddorp, The Netherlands). In the pilot study, TMZ was dissolved as $8 \mathrm{mg} / \mathrm{ml} 50 \%$ glucose jelly and $200 \mu \mathrm{l}$ was administered orally. For the imaging and final therapy studies, a $8 \mathrm{mg} / \mathrm{ml}$ solution TMZ was prepared in Oraplus (Paddock laboratories, Inc. Minneapolis USA) and $200 \mu \mathrm{l}$ aliquots were administered by oral gavage 5 days a week for 2 weeks resulting in a dose of $50 \mathrm{mg} / \mathrm{kg} /$ day TMZ.

\section{Radionuclides and peptides}

DOTA,Tyr ${ }^{3}$-octreotate was obtained from Mallinckrodt, St Louis, MO, and ${ }^{177} \mathrm{LuCl}_{3}$ was obtained from NRG Petten, The Netherlands. ${ }^{177}$ Lu-TATE was prepared as described previously [17] with a specific activity of $100 \mathrm{MBq} / 2.75 \mu \mathrm{g}$ peptide, and $10,20,30$ or $50 \mathrm{MBq}$ was injected intravenously (i.v.) in a volume of $200 \mu \mathrm{l}$ via the tail vein. Labelling of ${ }^{111}$ In-DTPA-octreotide (OctreoScan, Covidien, Petten, The Netherlands) was performed as described at a specific activity of $30 \mathrm{MBq} / 1.0 \mu \mathrm{g}$ DTPA-octreotide [17].

\section{SPECT/CT}

During scanning experiments, $2.0 \%$ isoflurane $/ \mathrm{O}_{2}$ gas anaesthesia was applied at $0.5 \mathrm{ml} / \mathrm{min}$. Twenty-four hours after injection of ${ }^{177} \mathrm{Lu}$-TATE or ${ }^{111}$ In-octreotide, helical SPECT/CT of the tumour region was performed with a four-headed NanoSPECT/CT system (BioScan, Washington DC USA) with nine pinhole mice collimators (diameter $1.4 \mathrm{~mm}$ ) per head. The scans were obtained using 24 projections of $120 \mathrm{~s}$ per projection and a quality factor of 0.7. SPECT scans were reconstructed iteratively on a $256 \times 256$ matrix, using HiSPECT NG software (Scivis, GmbH Göttingen Germany) and ordered subset expectation maximization (OSEM). The total amount of radioactivity (MBq) in the tumour was quantified by 3D quantification using InVivoScope software (IVS, Bioscan, Washington DC USA). To achieve accurate quantification, the camera was calibrated by scanning a $20-\mathrm{mL}$ polypropylene tube phantom filled with a known amount of ${ }^{177} \mathrm{Lu}$ or ${ }^{111} \mathrm{In}$ radioactivity. During scanning, body temperature of the mice was maintained using a heated bed.

\section{MRI}

Imaging was performed on a pre-clinical 7.0T scanner (Discovery MR901, Agilent technologies/GE Healthcare) with the standard imaging gradient set $(300 \mathrm{mT} / \mathrm{m}$, slew rate of $1000 \mathrm{mT} / \mathrm{m} / \mathrm{ms}-$ rise time $=300 \mu \mathrm{s})$. A $150-\mathrm{mm}$ transmit coil and four-channel surface coil $(5 \mathrm{~cm}$ FOV) were used to acquire all images.

DCE-MRI data were acquired following a bolus i.v. injection of Gadobutrol (Gadovist; Bayer Healthcare, Germany). The acquisition parameters used were repetition time $(\mathrm{TR})=10 \mathrm{~ms}$, echo time $(\mathrm{TE})=2 \mathrm{~ms}$, flip angle $12^{\circ}$, matrix size $=116 \times 116$ and slice thickness $=0.8 \mathrm{~mm}$ with a total imaging volume of 
$50 \times 50 \times 32 \mathrm{~mm}^{3}(\mathrm{x}, \mathrm{y}, \mathrm{z})$. Four k-space segments were acquired using a segmented readout sequence called TRICKS [18]. This resulted in a temporal resolution of $4.7 \mathrm{~s}$. Before contrast administration, four to five time points were acquired to obtain the baseline signal intensity. Prior to acquiring the DCEMRI image series, a saturation recovery $\mathrm{T} 1$ map was acquired using a spin echo sequence with varying TRs, settings: $\mathrm{TE}=8 \mathrm{~ms}, \mathrm{TR}=200,400,800$ and $1600 \mathrm{~ms}$. T2 maps were also acquired with a spin echo sequence varying TE, settings: $T R=1200 \mathrm{~ms}$, $\mathrm{TE}=8,16,25$ and $35 \mathrm{~ms}$. All mapping images were acquired with slice thickness $0.8 \mathrm{~mm}, 5 \mathrm{~cm}$ FOV and $256 \times 256$ matrix.

\section{Image analysis}

Analysis of the SPECT data: the concentration of activity in the tumours was calculated by dividing the total amount of activity in the tumour determined by 3D quantification with HiSPECT NG software through the $3 \mathrm{D}$ tumour volume determined during this quantification.

For analysis of the DCE-MRI data, we used two methods: semi-quantitative and quantitative analysis. All calculations were performed using Matlab (Mathworks co.). In semi-quantitative analysis, the signal-intensity time curves were used to determine the time to peak (TTP), maximum signal enhancement (Smax) and the area under the curve (AUC) for the total curve and also for the first $60 \mathrm{~s}$ (AUC60). The AUC and AUC60 were calculated using a triangulation algorithm. Furthermore, the wash-in was calculated as a linear slope from the first point before contrast enhancement to the first maximum. The wash-out was calculated from the slope of the first maximum to the measurement at $60 \mathrm{~s}$ after injection. The wash-out curve was not necessarily linear in shape, but using this method, we were able to discriminate the wide variety in wash-out kinetics. In order to calculate quantitative parameters from the DCE-MRI data, the signal-intensity time curves were converted to contrast-concentration time curves using a T1-map calibration. A pharmacokinetic compartment model could be fitted to these contrast-concentration time curves. Quantitative analysis consisted of calculation of $\mathrm{k}^{\text {trans }}$ and $\mathrm{k}_{\mathrm{ep}}$, calculated according to Tofts perfusion model [19]. A population-based average arterial input function (AIF) obtained from Weidensteiner [20] was used for consistency in the results. For the response to therapy, comparison of the tumour perfusion parameters was performed; regions of interest were drawn around the tumours, and mean parameter values were calculated. $\mathrm{k}^{\text {trans }}$ is the calculated rate constant for the passage of contrast agent into the tissue. The rate constant $\mathrm{k}_{\mathrm{ep}}$ is the reflux of contrast agent from tissue back to the blood. The results presented show the $\mathrm{k}^{\text {trans }}$ which performed slightly better than the $\mathrm{k}_{\mathrm{ep}}$ in this model due to the limited amount of wash-out in the 10-min scantime.

\section{In vitro autoradiography on tumours treated with TMZ during the imaging study}

Sections of $10 \mu \mathrm{m}$ were sliced from frozen tumours (Cryo-Star HM 560 M; Microm, Walldorf, Germany), mounted on Superfrost plus slides (Menzel, Braunschweig, Germany) and incubated with $10^{-9} \mathrm{M}{ }^{111}$ Inoctreotide with and without an excess $\left(10^{-6} \mathrm{M}\right)$ of unlabelled octreotide. Adjacent sections were stained with haematoxylin/eosin. Tumour sections were exposed to SR phosphor imaging screens (Packard Instruments Co., Meriden, USA) in X-ray cassettes. After 48-h exposure, screens were read by a Cyclone phosphor imager and analysed using OptiQuant 03.00 (Perkin Elmer, Groningen, The Netherlands). Autoradiogram quantification was expressed in density light units (DLU) per square millimetre.

\section{Statistics}

Prism software version 5.0 (Graph Pad) was used to analyse tumour growth and determine statistical significance between groups. One-way ANOVA was used for statistical analysis of tumour uptake, and results are given as mean \pm SD. A log rank test was performed for curve comparison.

\section{Results}

\section{${ }^{177}$ Lu-TATE dose-response study}

All three ${ }^{177}$ Lu-TATE groups showed delay of tumour growth compared with the control group (Fig. 2). As expected, the most significant tumour growth suppression was found in the $30 \mathrm{MBq}$ group, although complete response was not reached in any mouse.

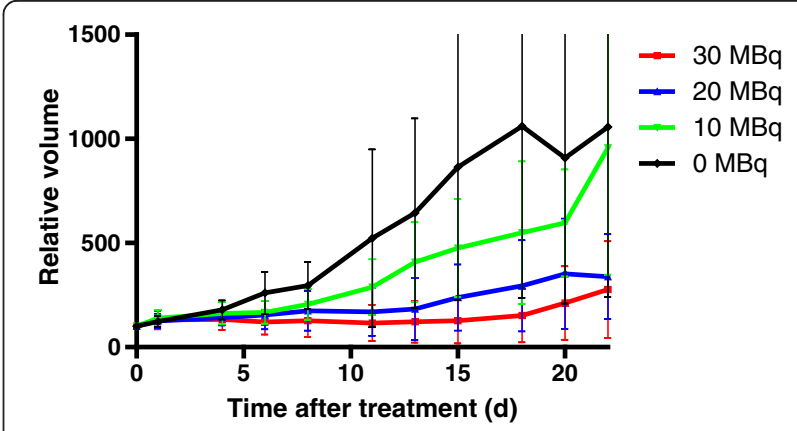

Fig. 2 Dose-finding study: H69 tumour volume as a percentage compared with day $0( \pm S D)$ after treatment with different amounts of ${ }^{177}$ Lu-TATE, seven mice/group 


\section{Imaging studies}

\section{Effect of single-agent treatment on tumour growth}

Treatment with either ${ }^{177} \mathrm{Lu}-\mathrm{TATE}$ or TMZ resulted in transient reduction in tumour size/volume, confirming previous results. However, the kinetics of the tumour response after the two treatments differed (Fig. 3a).

The average ${ }^{177} \mathrm{Lu}$ uptake in the four tumours in the PRRT group was $1.7 \pm 0.1 \mathrm{kBq} / \mathrm{mm}^{3}(3.4 \pm 0.2 \% \mathrm{IA} / \mathrm{g})$ at $24 \mathrm{~h}$ after administration of $50 \mathrm{MBq}{ }^{177} \mathrm{Lu}$-TATE. Maximum reduction of tumour volume was reached at $\sim$ day 14, after which the tumours increased in size again. After an average of 43 days, euthanasia was needed because the maximal allowed tumour size $\left(1800 \mathrm{~mm}^{3}\right)$ was reached.

In mice treated with TMZ, the tumour volumes increased until day 9 reaching maximum tumour sizes, after which decrease of tumour sizes was observed. At day 51, at the end of the imaging study, the average tumour volume increased again; however, at that time, none of the tumours exceeded a volume of $1800 \mathrm{~mm}^{3}$.

\section{Tumour perfusion during ${ }^{177}$ Lu-TATE or TMZ treatment}

Tumours subjected to TMZ and ${ }^{177}$ Lu-TATE initially showed a fast decrease in $\mathrm{k}^{\text {trans }}$, reaching minimum values at day $4\left((2.2 \pm 2) \times 10^{-3} \mathrm{~min}^{-1}\right.$ for $\left.{ }^{177} \mathrm{Lu}-\mathrm{TATE}\right)$ or day $5\left((2.0 \pm 2) \times 10^{-3} \mathrm{~min}^{-1}\right.$ for TMZ). When tumour size decreased, an increase in $\mathrm{k}^{\text {trans }}$ was measured. The local maximum in $\mathrm{k}^{\text {trans }}$ values was reached approximately 2 weeks after (start of) treatment. Tumours in the group receiving TMZ showed the highest $k^{\text {trans }}$ values at day $13\left((11 \pm 1) \times 10^{-3} \mathrm{~min}^{-1}\right)$; the ${ }^{177} \mathrm{Lu}$-TATE group's maximum $\mathrm{k}^{\text {trans }}$ value was reached at day 15 $\left((5.8 \pm 2) \times 10^{-3} \mathrm{~min}^{-1}\right)$. During further follow-up, the $\mathrm{k}^{\text {trans }}$ values decreased again in both the TMZ and ${ }^{177} \mathrm{Lu}$-TATE group.

\section{SSTR2 expression and uptake of ${ }^{111}$ In-octreotide before and after TMZ treatment}

In vitro autoradiography results showed no difference in SSTR2 expression of $\mathrm{H} 69$ xenografts before (day 0) or after (day 15 and day 28) TMZ treatment (Fig. 4a). Yet, SPECT imaging showed that at day 0 (average tumour

a

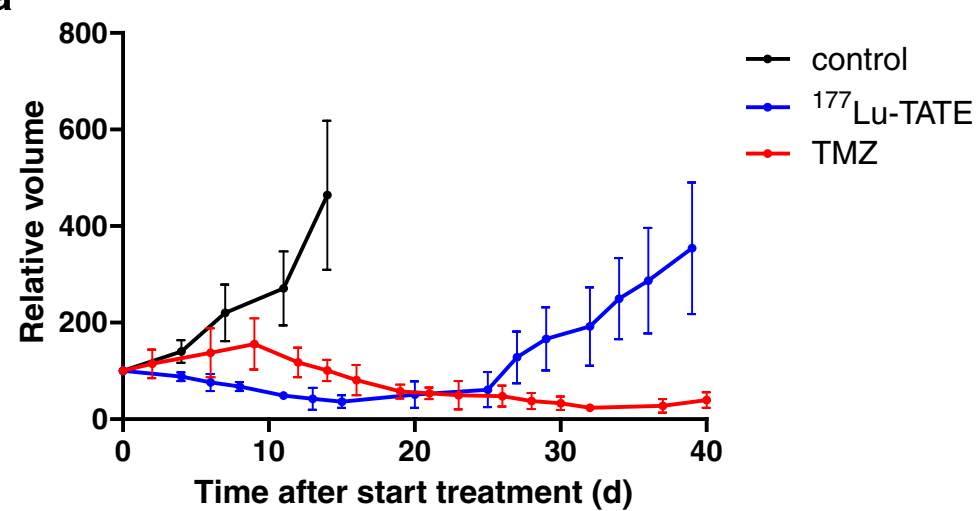

b

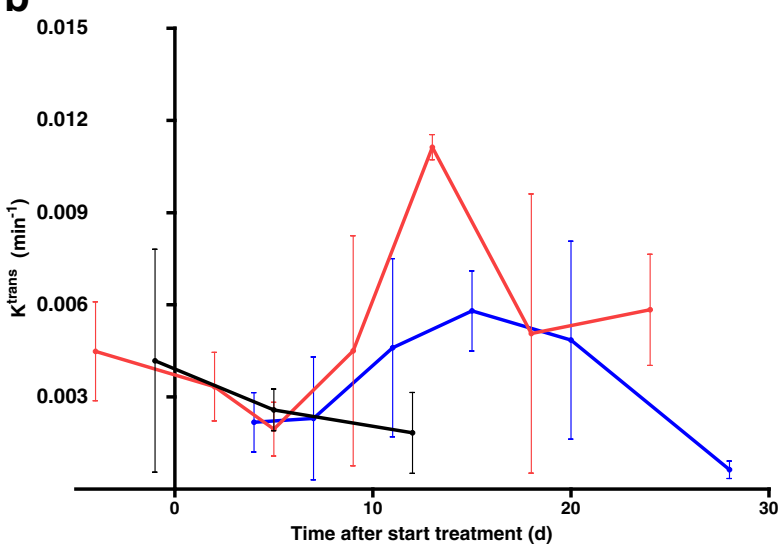

Fig. 3 Effect on $\mathrm{H} 69$ tumour volume (a) and tumour perfusion (b) of single-agent treatment. a Tumour volume as a percentage compared to day $0 \pm$ SD. $\mathbf{b}$ Average intra-tumoural $k^{\text {trans }}$ was calculated, and the presented data show the average across tumours with the SD. The control group $(n=3)$ (black line) received saline, the PRRT group $(n=4)$ was treated with $50 \mathrm{MBq}{ }^{177}$ Lu-TATE (blue line) on day 0, and the temozolomide $(\mathrm{TMZ})$ group $(n=7)$ (red line) was treated for 14 days with orally administered TMZ at a dose of $50 \mathrm{mg} / \mathrm{kg} /$ day 


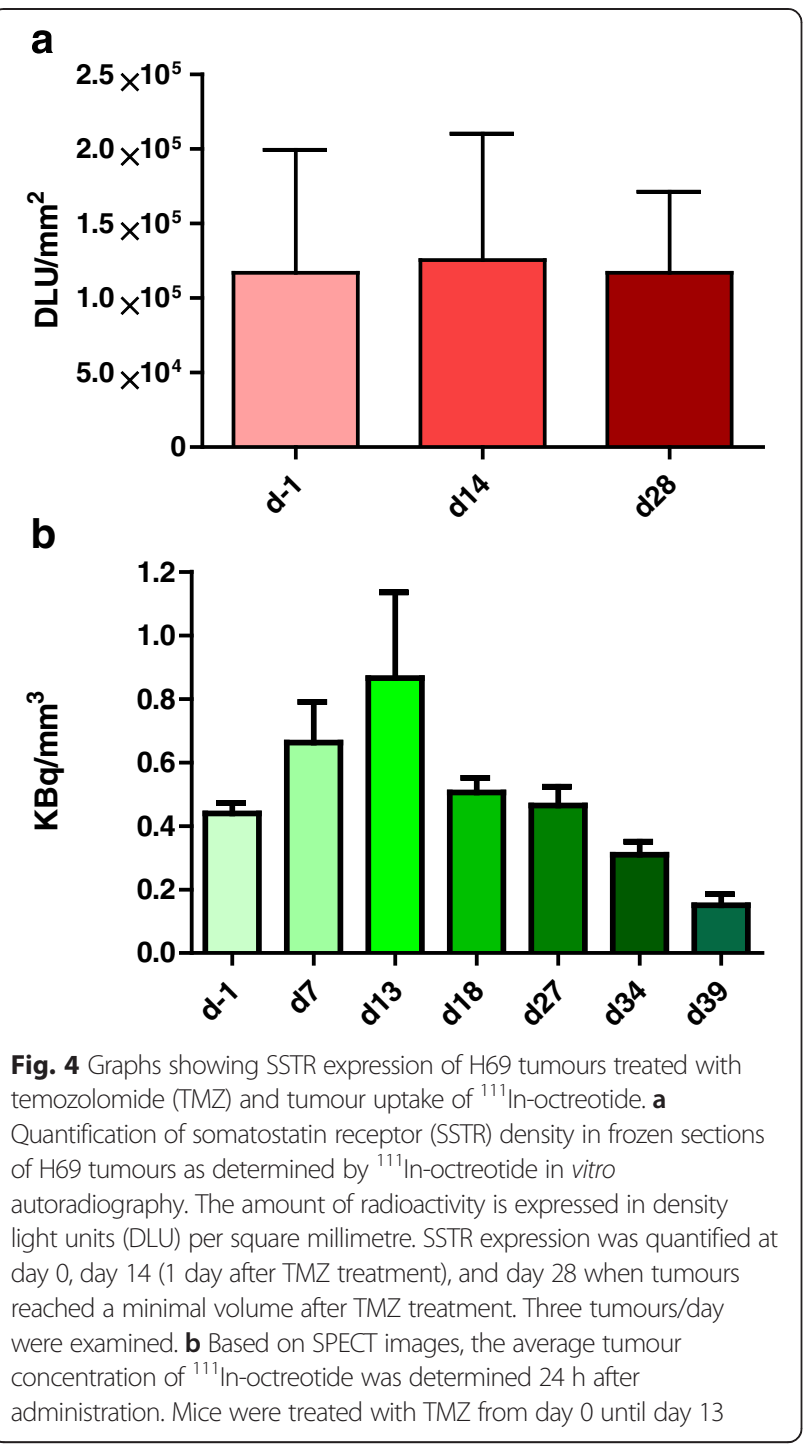

volume $456 \mathrm{~mm}^{3}$ ), the average radioactivity after injection of ${ }^{111}$ In-octreotide was $0.4 \pm 0.2 \mathrm{kBq} / \mathrm{mm}^{3}$ (1.5 \pm $0.4 \% \mathrm{IA} / \mathrm{g}$ ) $\mathrm{H} 69$ xenograft, while after 14 days of TMZ treatment, this was increased until $0.9 \pm 0.3 \mathrm{kBq} / \mathrm{mm}^{3}$ $(2.9 \pm 0.9 \% \mathrm{IA} / \mathrm{g})$ (average tumour volume $\left.442 \mathrm{~mm}^{3}\right)$. When the administration of TMZ was discontinued, the ${ }^{111} \mathrm{In}$-H69 uptake dropped again to $0.5 \pm 0.2 \mathrm{kBq} / \mathrm{mm}^{3}$ $(1.7 \pm 0.5 \% \mathrm{IA} / \mathrm{g})$ at day 18 and $0.5 \pm 0.2 \mathrm{kBq} / \mathrm{mm}^{3}(1,5 \pm$ $0.5 \% \mathrm{IA} / \mathrm{g})$ at day 27 , further declining until day 39 (Fig. 4b).

\section{Therapy study}

\section{Responses to the different treatment schedules}

As expected, all mice in the control group had to be euthanized due to excessive tumour growth. This was also true for the mice in the single-treatment groups with ${ }^{177} \mathrm{Lu}$-TATE (groups 1 and 2) or TMZ (group 3), albeit with a significant delay of 20-50 days (Fig. 5b). The median survival time (MST) to reach the maximum tumour size of $1800 \mathrm{~mm}^{3}$ was 32 days for the mice in the control group versus 53 days for the single ${ }^{177} \mathrm{Lu}$ TATE group 1 and 74 days for the double ${ }^{177} \mathrm{Lu}$-TATE group 2. The single TMZ group 3 reached an extended MST of 81 days.

In all three groups treated with a combination of ${ }^{177} \mathrm{Lu}$-TATE and TMZ, an additive effect of the two treatments was determined. Since in several mice complete tumour response was reached, MST could not be determined. Regarding survival, the difference between the best performing single-therapy group 3 (TMZ) and group 4 (TMZ 14 days after ${ }^{177}$ Lu-TATE) was significant $(p=0.046)$, whereas the other combination groups performed even better. Thus, the applied treatment schedules in these three groups had a striking impact on tumour response. In group 4, still $57 \%$ of tumours reached a volume of $1800 \mathrm{~mm}^{3}$ before the end of the study at day 123 . When ${ }^{177} \mathrm{Lu}$-TATE and TMZ were combined from the start (group 5), only $25 \%$ of tumours reached this maximum size. By far, the best result was obtained in group 6 with ${ }^{177} \mathrm{Lu}$-TATE administered after 14 days TMZ treatment. Only one tumour (10 \%) escaped from treatment, whereas the other tumours showed complete response.

\section{Tumour uptake of ${ }^{177}$ Lu-TATE}

The uptake of ${ }^{177}$ Lu-TATE in H69 tumours was quantified $24 \mathrm{~h}$ after administration of $30 \mathrm{MBq}{ }^{177} \mathrm{Lu}$-TATE based on SPECT/CT imaging. As reference, the average ${ }^{177} \mathrm{Lu}$-tumour uptake was $1.7 \pm 0.2 \mathrm{kBq} / \mathrm{mm}^{3}$ without previous treatment. When after 14 days a second dose of ${ }^{177} \mathrm{Lu}$-TATE was given, a comparable ${ }^{177} \mathrm{Lu}$-tumour concentration of $1.7 \pm 0.1 \mathrm{kBq} / \mathrm{mm}^{3}(5.6 \pm 0.3 \% \mathrm{IA} / \mathrm{g})$ was found. However, in mice receiving ${ }^{177} \mathrm{Lu}$-TATE on day 14 after initial TMZ for 14 days, a significantly higher uptake of $2.2 \pm 0.5 \mathrm{kBq} / \mathrm{mm}^{3}(7.5 \pm 1.5 \%)$ was determined ( $p=0.013)$ (Fig. 5c).

\section{Discussion}

Despite the fact that significant tumour response rates have been reported after treatment of NET patients with ${ }^{177} \mathrm{Lu}$-TATE or [90Y-DOTA]-D-Phe1-Tyr3-octreotide (90Y-DOTATOC) [21, 22], complete responses are still rare, urging for improvements of PPRT protocols. TMZ is currently being applied in combination with radiotherapy for treatment of glioblastoma patients [23]. TMZ (+ cap) is also effective in NET patients [24, 25]. Therefore, we examined in mice if this alkylating agent offered synergistic effects when combined with ${ }^{177} \mathrm{Lu}$-TATE PRRT.

In this pre-clinical study, we aimed to elucidate the most effective treatment schedule of the TMZ and PRRT combination. We applied a TMZ dose of $50 \mathrm{mg} / \mathrm{kg}$ daily for 2 weeks, which appeared to be an effective dose in 

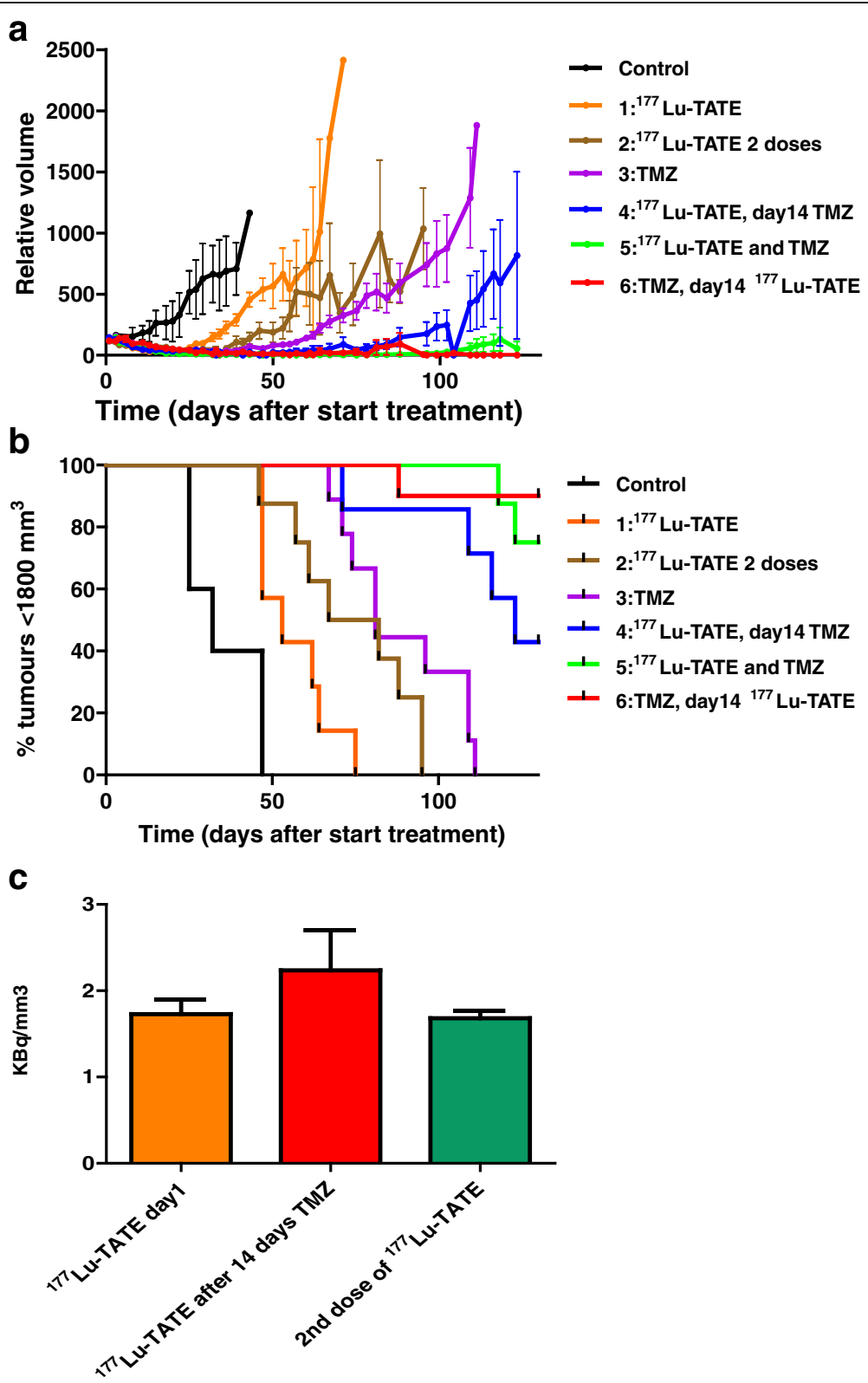

Fig. 5 Graphs showing for each treatment group a average $\mathrm{H} 69$ tumour volume, $\mathbf{b}$ percentage of animals with tumours $<1800 \mathrm{~mm}^{3}$, and $\mathbf{c}$ average tumour radioactivity at $24 \mathrm{~h}$ after administration of ${ }^{177}$ Lu-TATE A. Average tumour volume as a percentage compared with day 0 . Tumours $>1800$ were taken out of the follow-up, which influenced the average tumour volume shown in the curves. The control group was treated with placebo, $30 \mathrm{MBq}$ ${ }^{177}$ Lu-TATE was i.v. administered at day 0 to mice in groups 1, 4 and 5, at day 14 for group 6 and both at day 0 and day 14 for group 2 . TMZ was administered orally once daily for 14 days at a dose of $50 \mathrm{mg} / \mathrm{kg}$ from day 0 to mice in groups 3, 4 and 6, starting at day 14 for group 5 . Eight to ten mice/group. c Average tumour radioactivity: orange bar: groups 1, 2 (first dose), 4, 5; red bar: group 6; green bar: group 2 (second dose). Numbers, respectively, 14, 6 and 6 mice/group

our H69 model not resulting in complete responses. The same was true for a dose of $30 \mathrm{MBq}{ }^{177} \mathrm{Lu}$-TATE leading to a significant delay of H69-tumour size increase.

The human small cell lung cancer (SCLC) H69 cell line, used in our studies, expresses SSTR2 in high densities. As a subtype of NETs, SCLC accounts for about $20 \%$ of all lung cancers [26] and shows a 5-year survival rate of only $20 \%$ [26]. For this type of cancer, there is a clear need to find therapeutic methods resulting in better survival. Several chemotherapeutics, including TMZ, are being used to treat SCLC [27], making the H69 cell line a suitable model for pre-clinical in vivo PRRT research using radiolabelled SST analogues [28]. To study dosimetry and tumour response, Schmitt et al. applied several activity doses of ${ }^{177}$ Lu-TATE for PRRT of H69 tumour-bearing mice [28, 29]. In their study, tumours 
showed a significantly higher uptake of radioactivity compared with all normal organs [28]. In a therapy study, using substantially larger tumours than in our study (respectively, 1000 and $2000 \mathrm{~mm}^{3}$ at day 0), increasing growth delays using doses of 45, 60 and $120 \mathrm{MBq}$ or two fractions of $45 \mathrm{MBq}{ }^{177} \mathrm{Lu}$-TATE were found [29].

In the clinical trials in which PRRT was combined with capecitabine and TMZ, the focus mainly has been on the radio-sensitizing effects of the chemotherapeutics $[8,30]$, not considering other effects these agents might have on tumour characteristics. In our opinion, the potential influence of chemotherapeutics on tumour perfusion and SSTR2 expression is of major importance as well, to determine an optimal scheme for the combination of PRRT with chemotherapeutics.

In this study, we measured an increase of H69-tumour perfusion after TMZ treatment. The highest values after 14 days of TMZ treatment coincide with a peak in the uptake of radiolabelled octreotide. The latter observation was confirmed during therapy, as ${ }^{177}$ Lu-uptake in $\mathrm{H} 69$ tumours after ${ }^{177} \mathrm{Lu}$-TATE administration was significantly higher when mice were pre-treated for 14 days with TMZ. This was not the case when pre-treatment consisted of an additional dose of ${ }^{177} \mathrm{Lu}$-TATE.

This increased tumour uptake/retention of radioactivity after TMZ treatment can be explained by different phenomena. A relation between tumour volume and concentration of radioactivity has been described, indicating an increased concentration of radioactivity in smaller tumours [28]. In our studies, however, the average tumour size was in the same range at day 0 and at day 13, respectively, a mean tumour volume of $456 \pm$ 122 versus $442 \pm 66 \mathrm{~mm}^{3}$, demonstrating that the peak of radioactivity uptake at day 13 was not influenced by tumour volume. At later time points, when tumour sizes continued to decrease as a result of TMZ treatment, also the concentration of ${ }^{111}$ In-octreotide decreased.

An increased level of SSTR2 expression might also explain the peak of radiopeptide uptake after 14 days of TMZ. Using in vitro studies, Fueger et al. showed increased SSTR2 expression in pancreatic tumour cells 4 days after exposure to several chemotherapeutics, not including TMZ $[11,12]$. This phenomenon could not explain our findings in the current study, however, as we found no differences in SSTR2 expression prior to or after TMZ treatment, when in vivo H69-uptake of ${ }^{111} \mathrm{In}$-octreotide peaked.

Therefore, increased tumour perfusion caused by TMZ treatment offers the best explanation for the raised levels of ${ }^{111} \mathrm{In}$ and ${ }^{177} \mathrm{Lu}$ tumour uptake, as was explored and confirmed by application of measurement of perfusion parameters by DCE-MRI.

In multiple studies, TMZ, when administered in a metronomic (repetitive, low dose) schedule, has been demonstrated to have anti-angiogenic effects that may result in normalized tumour vasculature depending on the administered TMZ dose [31, 32]. Therefore, direct or indirect anti-angiogenic effect of chemotherapeutics can improve tumour perfusion and reduce the interstitial pressure [33], enabling enhanced delivery to the tumour of therapeutic compounds, including radiolabelled peptides. Our measurements with DCE-MRI support the suggestion that there is an important relationship between functional vasculature and radiopeptide uptake [34].

Considering the anti-tumour response, a small but not significant $(p=0.28)$ difference was found between group 5 (concurrent ${ }^{177} \mathrm{Lu}$-TATE and TMZ) and group 6 $\left({ }^{177} \mathrm{Lu}\right.$-TATE after 14 days TMZ treatment) regarding CR, with 75 versus $90 \% \mathrm{CR}$, respectively. However, when we compare group 6 with group 4 (the group in which ${ }^{177} \mathrm{Lu}$-TATE was administered at day 1 and TMZ treatment started at day 14), a striking and significant difference $(p=0.046)$ between those groups was found, in agreement with the fact that TMZ potentiates the effect of ${ }^{177} \mathrm{Lu}$-TATE.

Therefore, the optimal response found in the group receiving ${ }^{177}$ Lu-TATE after TMZ treatment might be based on a combination of factors:

1. Increased uptake of ${ }^{177} \mathrm{Lu}$-TATE because of enhanced perfusion resulting in a higher absorbed tumour radiation dose and therefore an increased anti-tumour response [35].

2. Increased radiosensitivity induced by TMZ. The cytotoxicity of TMZ is primarily due to alkylation at the $O 6$ position of guanine combined with an additional alkylation at the $N 7$ position. TMZ has been reported to act synergistically with radiation therapy, as alkylated guanine has been reported to be radio-sensitizing [9], as was shown in multiple types of cancer cells $[9,36]$. As the half-life of ${ }^{177} \mathrm{Lu}$ is 6.7 days [28], also the group receiving ${ }^{177} \mathrm{Lu}$-TATE at the same day that TMZ treatment was started might have had some benefit from the radiosensitizing effects of TMZ.

3. Increased oxygenation might have contributed to improved therapeutic responses, as was demonstrated for radiation therapy [37]. After betaparticle radiation, DNA damage occurs as a result of the creation of free oxygen radicals [38], so the effect of ${ }^{177} \mathrm{Lu}$-TATE treatment might be enhanced when tumour oxygenation is improved. The mice receiving ${ }^{177}$ Lu-TATE 14 days prior to TMZ treatment did not have this benefit.

Despite the fact that our model has been carefully chosen, it has important differences from the patient situation. Differences in, e.g. tumour growth rate might 
influence the outcome of these studies in a clinical setting. Therefore, the translational value of our findings into the clinic remains to be proven.

During our combination therapy study, no signs of severe toxicity like, e.g. remarkable loss of weight have occurred. Nevertheless, during PRRT as well as chemotherapy, toxicity is an aspect of great concern. In a clinical study, a treatment scheme in which PRRT was combined with capacetabine and TMZ has been shown to be safe [8]. Considering increased uptake of radionuclides after TMZ treatment, in our opinion, this is likely to be solely applicable to the tumour because of its immature vasculature. However, further investigation on toxicity and uptake of radionuclides by the normal organs is warranted.

\section{Conclusions}

The use of SPECT/CT and MRI enabled us to optimize a treatment schedule for the combination of PRRT and TMZ in H69-xenografted nude mice. Increased perfusion following TMZ pre-treatment, determined by DCEMRI, coinciding with increased uptake of ${ }^{177} \mathrm{Lu}$-TATE as proven by SPECT/CT, was reflected by the induced therapeutic effects we observed.

\section{Compliance with ethical standards Ethical approval}

All applicable international, national and/or institutional guidelines for the care and use of animals were followed.

\section{Competing interests}

S.M. Bison declares that he has no competing interests, J.C. Haeck declares that he has no competing interests, $\mathrm{K}$. Bol declares that she has no competing interests, S.J. Koelewijn declares that he has no competing interests, H.C. Groen declares that he has no competing interests, M. Melis declares that she has no competing interests, J. Veenland declares that she has no competing interests, M.R. Bernsen declares that she has no competing interests, M. De Jong declares that she has no competing interests.

\section{Authors' contributions}

All authors read and approved the final manuscript.

\section{Funding}

This study was funded under grant "Erasmus MC R 2008-4037".

\section{Author details}

${ }^{1}$ Department of Nuclear Medicine, Erasmus MC, Postbus 2040, Rotterdam 3000, CA, The Netherlands. 'Department of Radiology, Erasmus MC, Postbus 2040, Rotterdam 3000, CA, The Netherlands. ${ }^{3}$ Department of Medical Informatics, Erasmus MC, Postbus 2040, Rotterdam 3000, CA, The Netherlands.

\section{Received: 15 September 2015 Accepted: 27 October 2015}

Published online: 09 November 2015

\section{References}

1. Kwekkeboom DJ, de Herder WW, van Eijck CH, Kam BL, van Essen M, Teunissen JJ, et al. Peptide receptor radionuclide therapy in patients with gastroenteropancreatic neuroendocrine tumors. Semin Nucl Med. 2010;40(2):78-88.
2. Laverman P, Sosabowski JK, Boerman OC, Oyen WJ. Radiolabelled peptides for oncological diagnosis. Eur J Nucl Med Mol Imaging. 2012;39 Suppl 1:S78-92.

3. Krenning EP, de Jong M, Kooij PP, Breeman WA, Bakker WH, de Herde WW, et al. Radiolabelled somatostatin analogue(s) for peptide receptor scintigraphy and radionuclide therapy. Ann Oncol. 1999;10 Suppl 2:S23-9.

4. Yao JC, Hassan M, Phan A, Dagohoy C, Leary C, Mares JE, et al. One hundred years after "carcinoid": epidemiology of and prognostic factors for neuroendocrine tumors in 35,825 cases in the United States. J Clin Oncol. 2008;26(18):3063-72

5. Reubi JC, Kvols LK, Waser B, Nagorney DM, Heitz PU, Charboneau JW, et al. Detection of somatostatin receptors in surgical and percutaneous needle biopsy samples of carcinoids and islet cell carcinomas. Cancer Res. 1990;50(18):5969-77.

6. Bodei $\mathrm{L}$ et al. Peptide receptor radionuclide therapy with (1)(7)(7)LuDOTATATE: the IEO phase I-II study. Eur J Nucl Med Mol Imaging. 2011;38(12):2125-35.

7. Rich TA, Shepard RC, Mosley ST. Four decades of continuing innovation with fluorouracil: current and future approaches to fluorouracil chemoradiation therapy. J Clin Oncol. 2004;22(11):2214-32.

8. Claringbold PG, Price RA, Turner JH. Phase I-II study of radiopeptide $177 \mathrm{Lu}$ octreotate in combination with capecitabine and temozolomide in advanced low-grade neuroendocrine tumors. Cancer Biother Radiopharm. 2012;27(9):561-9.

9. Bobola MS, Kolstoe DD, Blank A, Silber JR. Minimally cytotoxic doses of temozolomide produce radiosensitization in human glioblastoma cells regardless of MGMT expression. Mol Cancer Ther. 2010;9(5):1208-18.

10. van Essen M, Krenning EP, Kam BL, de Herder WW, van Aken MO, Kwekkeboom DJ. Report on short-term side effects of treatments with $177 \mathrm{Lu}$-octreotate in combination with capecitabine in seven patients with gastroenteropancreatic neuroendocrine tumours. Eur J Nucl Med Mol Imaging. 2008;35(4):743-8.

11. Fueger BJ, Hamilton G, Raderer M, Pangerl T, Traub T, Angelberger P, et al. Effects of chemotherapeutic agents on expression of somatostatin receptors in pancreatic tumor cells. J Nucl Med. 2001:42(12):1856-62.

12. Nayak TK, Atcher RW, Prossnitz ER, Norenberg JP. Enhancement of somatostatin-receptor-targeted (177)Lu-[DOTA(0)-Tyr(3)]-octreotide therapy by gemcitabine pretreatment-mediated receptor uptake, up-regulation and cell cycle modulation. Nucl Med Biol. 2008;35(6):673-8.

13. Pasquier E, Tuset MP, Street J, Sinnappan S, Mackenzie KL, Braguer D, et al. Concentration- and schedule-dependent effects of chemotherapy on the angiogenic potential and drug sensitivity of vascular endothelial cells. Angiogenesis. 2013;16(2):373-86.

14. Hirst TC, Vesterinen HM, Sena ES, Egan KJ, Macleod MR. Whittle IR Systematic review and meta-analysis of temozolomide in animal models of glioma: was clinical efficacy predicted? Br J Cancer. 2013;108(1):64-71.

15. Palma JP, Wang YC, Rodriguez LE, Montgomery D, Ellis PA, Bukofzer $G$, et al. ABT-888 confers broad in vivo activity in combination with temozolomide in diverse tumors. Clin Cancer Res. 2009;15(23):7277-90.

16. Kitange GJ, Carlson BL, Schroeder MA, Grogan PT, Lamont JD, Decker PA, et al. Induction of MGMT expression is associated with temozolomide resistance in glioblastoma xenografts. Neuro Oncol. 2009;11(3):281-91.

17. Breeman W, d.E.a.K.E. Effects of quenchers on the radiochemical purity of 111In-labeled peptides. J Nucl Med. 2007;48(Supplement 2):73P.

18. Korosec FR, Frayne R, Grist TM, Mistretta CA. Time-resolved contrast-enhanced 3D MR angiography. Magn Reson Med. 1996;36(3):345-51.

19. Tofts PS, Brix G, Buckley DL, Evelhoch JL, Henderson E, Knopp MV, et al. Estimating kinetic parameters from dynamic contrast-enhanced T(1)-weighted MRI of a diffusable tracer: standardized quantities and symbols. J Magn Reson Imaging. 1999;10(3):223-32.

20. Weidensteiner C, Rausch M, McSheehy PM, Allegrini PR. Quantitative dynamic contrast-enhanced MRI in tumor-bearing rats and mice with inversion recovery TrueFISP and two contrast agents at 4.7 T. J Magn Reson Imaging. 2006;24(3):646-56.

21. van Essen M, Krenning EP, Bakker, W. H, de Herder WW, van Aken MO, Kwekkeboom DJ. Peptide receptor radionuclide therapy with $177 \mathrm{Lu}$ octreotate in patients with foregut carcinoid tumours of bronchial, gastric and thymic origin. Eur J Nucl Med Mol Imaging. 2007;34(8):1219-27.

22. Waldherr C, Pless M, Maecke HR, Haldemann A, Mueller-Brand J. The clinical value of [90Y-DOTA]-D-Phe1-Tyr3-octreotide 
(90Y-DOTATOC) in the treatment of neuroendocrine tumours: a clinical phase II study. Ann Oncol. 2001;12(7):941-5.

23. Parisi S, Corsa P, Raguso A, Perrone A, Cossa S, Munafò T, et al. Temozolomide and radiotherapy versus radiotherapy alone in high grade gliomas: a very long term comparative study and literature review. Biomed Res Int 2015:2015:620643.

24. Fine RL, Gulati AP, Krantz BA, Moss RA, Schreibman S, et al. Capecitabine and temozolomide (CAPTEM) for metastatic,

well-differentiated neuroendocrine cancers: The Pancreas Center at Columbia University experience. Cancer Chemother Pharmacol. 2013;71(3):663-70.

25. Ekeblad S, Sundin A, Janson ET, Welin S, Granberg D, Kindmark H, et al. Temozolomide as monotherapy is effective in treatment of advanced malignant neuroendocrine tumors. Clin Cancer Res. 2007;13(10):2986-91.

26. Simon GR, Wagner H. Small cell lung cancer. Chest. 2003;123(1 Suppl):259S-71S.

27. Pietanza MC, Kadota K, Huberman K, Sima CS, Fiore JJ, Sumner DK, et al. Phase II trial of temozolomide in patients with relapsed sensitive or refractory small cell lung cancer, with assessment of methylguanine-DNA methyltransferase as a potential biomarker. Clin Cancer Res. 2012;18(4):1138-45.

28. Schmitt A, Bernhardt P, Nilsson O, Ahlman H, Kolby L, Schmitt J, et al. Biodistribution and dosimetry of $177 \mathrm{Lu}$-labeled [DOTA0, Tyr3]octreotate in male nude mice with human small cell lung cancer. Cancer Biother Radiopharm. 2003;18(4):593-9.

29. Schmitt A, Bernhardt P, Nilsson O, Ahlman H, Kolby L, Maecke HR, et al. Radiation therapy of small cell lung cancer with 177Lu-DOTA-Tyr3octreotate in an animal model. J Nucl Med. 2004;45(9):1542-8.

30. Barber TW, Hofman MS, Thomson BN, Hicks RJ. The potential for induction peptide receptor chemoradionuclide therapy to render inoperable pancreatic and duodenal neuroendocrine tumours resectable. Eur I Surg Oncol. 2012;38(1):64-71.

31. Lam T, Hetherington JW, Greenman J, Little S, Maraveyas A. Metronomic chemotherapy dosing-schedules with estramustine and temozolomide act synergistically with anti-VEGFR-2 antibody to cause inhibition of human umbilical venous endothelial cell growth. Acta Oncol. 2007;46(8):1 169-77.

32. Kim JT, Kim JS, Ko KW, Kong DS, Kang CM, Kim MH, et al. Metronomic treatment of temozolomide inhibits tumor cell growth through reduction of angiogenesis and augmentation of apoptosis in orthotopic models of gliomas. Oncol Rep. 2006;16(1):33-9.

33. Jain RK. Normalizing tumor microenvironment to treat cancer: bench to bedside to biomarkers. J Clin Oncol. 2013;31(17):2205-18.

34. Bol K, Haeck JC, Groen HC, Niessen WJ, Bernsen MR, de Jong M, et al. Can DCE-MRI explain the heterogeneity in radiopeptide uptake imaged by SPECT in a pancreatic neuroendocrine tumor model? PLOS One. 2013:8(10):e77076.

35. Bernhardt P, Oddstig, J, Kolby L, Nilsson O, AhIman H, Forssell-Aronsson E. Effects of treatment with (177)Lu-DOTA-Tyr(3)-octreotate on uptake of subsequent injection in carcinoid-bearing nude mice. Cancer Biother Radiopharm. 2007:22(5):644-53.

36. Atallah E, Flaherty L. Treatment of metastatic malignant melanoma. Curr Treat Options Oncol. 2005;6(3):185-93.

37. Sonveaux P, Végran F, Schroeder T, Wergin MC, Verrax J, Rabbani ZN et al. Targeting lactate-fueled respiration selectively kills hypoxic tumor cells in mice. J Clin Invest. 2008;118(12):3930-42.

38. J, B., Radiation protection (Green Book). Chapter 4-biological effects of radiation. New Brunswick Power Corporation, 2001: p. 87-108.

\section{Submit your manuscript to a SpringerOpen ${ }^{\circ}$ journal and benefit from:}

- Convenient online submission

- Rigorous peer review

- Immediate publication on acceptance

- Open access: articles freely available online

- High visibility within the field

- Retaining the copyright to your article

Submit your next manuscript at $\gg$ springeropen.com 